\title{
Dynamic Behavior of Materials
}

\author{
K.A. Dannemann • V.B. Chalivendra • B. Song
}

Published online: 2 February 2012

(C) Society for Experimental Mechanics 2012

The dynamic behavior of materials is a subject of everincreasing interest to the technical community owing to applications ranging from shock and blast to crash, impact and ballistics. Hence, it has relevance to government, industry and academia. The enhanced interest in dynamic behavior is evident from the increase in the number of papers in Experimental Mechanics on this topic, as well as expansion of the Dynamic Behavior sessions at the SEM annual conferences. Since inauguration of the SEM Dynamic Behavior Technical Division in 2005, presentations on this topic at the annual conference have increased from two sessions ( 10 papers) in 2005 to two tracks ( $\sim 150$ papers) in 2009 and 2010 . This level of interest prompted the $E M$ editor to suggest a special issue to address current issues on the dynamic behavior of materials.

This special issue of Experimental Mechanics includes nine papers addressing topics of immediate interest to this technical community. The papers were selected from the written papers submitted to the Dynamic Behavior track at the 2010 SEM Annual Conference on Experimental and Applied Mechanics, Indianapolis, IN, USA, June 7-10, 2010. The major subject areas are: 1) Advancements in high strain rate testing, 2) Dynamic response of various materials, 3) Dynamic failure and fracture, and 4) Modeling of dynamic events.

K.A. Dannemann $(\bowtie)$

Southwest Research Institute,

San Antonio, TX, USA

e-mail: kdannemann@swri.org

V.B. Chalivendra

University of Massachusetts-Dartmouth,

N. Dartmouth, MA, USA

B. Song

Sandia National Laboratories,

Livermore, CA, USA
Hopkinson/Kolsky bar techniques are the most commonly used method for characterizing the high strain rate response of materials. Current dynamic testing methods can be linked to the pioneering work of Hopkinson [1] and Kolsky [2] in applying stress wave experiments to evaluate dynamic material response, and to Lindholm and co-workers [3] in reducing this technique to practice. They [3] developed a methodology for deriving the stress-strain response of a material using transient pulse shapes acquired from strain gages on both bars. The strain rate range for traditional Kolsky bar systems ranges from $10^{2} \mathrm{~s}^{-1}$ to $10^{4} \mathrm{~s}^{-1}$. Higher strain rates can be achieved by reducing the specimen size and the bar diameter [4]. Small (few mm or sub-millimeter) diameter Kolsky bar systems have been developed which extend the strain rate range beyond $100,000 \mathrm{~s}^{-1}$. However, strain gage measurement of the longitudinal stress waves in the bars becomes impractical at the small scale. The paper by Casem, Grunschel and Schuster, in this special issue of Experimental Mechanics, demonstrates the feasibility of optical techniques for replacing traditional strain gage measurements in miniaturized systems.

The dynamic tension or compression response of materials is readily obtained with traditional Kolsky bar systems. Pure shear data can also be obtained with a torsion bar. This is detailed in the paper by Hokka, et al. on the high strain rate torsion response of ultra-fine grained aluminum. Modifications to traditional Kolsky bar systems have expanded the types of high strain rate tests that can be conducted using these systems. For example, Anton and Subhash [5] used a modified bar system with a small diameter incident bar to measure dynamic Vickers hardness for brittle materials. Nie, Chen, et al. [6] conducted dynamic flexural strength tests on glass through implementation of a four-point bend configuration in the Hopkinson bar. Nie and Chen also devised a ring-on-ring technique for measuring the dynamic equibiaxial flexural strength of glass at temperatures up to 
$750^{\circ} \mathrm{C}$ using non-contact specimen heating. Their paper is included in this special issue, along with a paper by Huskins, et al. which further details Kolsky bar modifications for a heating system designed to reduce cold contact time during high temperature testing. The paper by Zhao, et al. reports modifications to a traditional bar system to evaluate the compression-shear response of a polymer bonded explosive (PBX). Their testing apparatus utilizes an incident bar with a wedge-shaped end and two transmission bars to evaluate the compression-shear response.

Four papers in this special issue address novel testing methods, and advances in testing methodology. However, understanding of the dynamic material response is critical to achieving design enhancements (e.g., improved armor systems, blast-resistant structures). This includes the onset and development of damage, as well as dynamic failure, in metals, ceramics, glasses and soft materials. Several other papers in this issue address dynamic material response and damage development.

Advances in digital image correlation (DIC) systems and techniques over the last decade have aided with this endeavor. The paper by Hokka, et al. demonstrates the benefit of DIC towards understanding the onset and progression of shear damage in ultrafine grain aluminum alloys during torsion testing. The application of DIC for interpreting the shock response of sandwich composites using a graded core and a polyurea layer are highlighted in the paper by Shukla, et al. Lamberson, Eliasson and Rosakis utilized optical techniques of caustics and photoelasticity, combined with high speed photography, to analyze crack growth behavior in brittle polymers after hypervelocity impacts at velocities of 3 to $7 \mathrm{~km} / \mathrm{s}$.

The dynamic failure of ceramic targets is further discussed in Bourne's paper in this issue. His review of material shock response and target preconditioning shows a correlation with ballistic target penetration, indicating a strong effect of the initial loading impulse on dynamic phenomena. Numerical modeling and simulation of dynamic events can provide further insight into the damage and failure process. This is demonstrated in the paper by Todd and co-workers where a DaMaGe Initiated Reaction (DMGIR) model is presented that numerically predicts damage-induced initiation of explosives. Synergistic efforts between the experimental and modeling communities will provide further benefits to the experimental mechanics community through improved experimental designs and interpretation of test results.

The guest editors gratefully acknowledge the technical contributions and dedicated efforts of all authors in making this special issue possible. Special thanks are also extended to Professor Hareesh Tippur, Technical Editor, and the Experimental Mechanics editorial staff (Jen Tingets and Alessandra de la Vega) for their assistance with this special issue on the Dynamic Behavior of Materials.

\section{References}

1. Hopkinson B (1914) A method of measuring the pressure produced in the detonation of high explosives or by the impact of bullets. Phil Trans Roy Soc London A 13:437-456

2. Kolsky H (1949) An investigation of the mechanical properties of materials at very high rates of loading. Proc Phys Soc London B2:676-700

3. Lindholm US, Yeakley LM (1968) High strain rate testing: tension and compression. Exp Mech 8:1-9

4. Jia D, Ramesh KT (2004) A rigorous assessment of the benefits of miniaturization in the Kolsky bar system. Exp Mech 44:445-454

5. Anton RJ, Subhash G (2000) Dynamic Vickers indentation of brittle materials. Wear 239(1)

6. Nie X, Chen W, Wereszczak AA, Templeton DW (2009) Effect of loading rate and surface conditions on the flexural strength of borosilicate glass. J Am Ceram Soc 92(6):1287-1295 